the traditional concept of domainindependent mechanisms wherein different "contents" compete for limited processing resources. "It seems to me", Fodor writes, "that the notion of a vertical faculty is among the great historical contributions to the development of theoretical psychology", an evaluation with which I fully concur.

A more pointed issue, however, is: are Gall's views correct? Fodor now advances a taxonomy of mentation that specifies those aspects of mind that do seem to be "modular" (in Gall's sense) and those that do not. Fodor distinguishes between transducers (the sense organs that encode proximal stimulation into neural signals), interface systems that compute the structure and character of the distal objects that correspond with particular proximal stimulations, and central systems concerned with the fixation of belief. Interface systems, Fodor argues, are modular, central processes are not. The interface systems are the various mechanisms of domain-specific perceptual analysis plus language, a somewhat "odd category", as Fodor remarks, from the viewpoint of any traditional fractionation of the mind. What does unify the class functionally is that its members all "represent the world as to make it accessible to thought", although they do so in radically distinct ways: "What underwrites the correlation between visual stimulations and distal layouts are (roughly) the laws of light reflectance. Whereas, what underwrites the correlation between token utterances and distal layouts is (roughly) a convention of truth telling". Granted that Fodor's functional characterization is correct, we can then inquire why, in the evolution of the brain, modular systems should have been selected for precisely this class.

The operation of systems that "present the world to thought" must be fast and mandatory if the organism is to survive in a world of predators, moving cars or academic discussion. Interface systems achieve speed by having built in to them a "theory" of the domain to which they are responsive. The algorithm that derives the intrinsic shape of a moving object is constrained by the principle of rigidity: if a collection of moving points has a unique interpretation as a rigid body in motion, "see" that interpretation. Similarly, effective algorithms for parsing sentences must have available to them the structural principles of universal grammar. (Chomsky's Cartesian notion of innately known principles thus fits well with Gall's notion of a "vertical faculty".) The domain-specificity of cognitive modules therefore follows from the specificity of the types of information they must contain.

Fodor further argues that interface systems are "informationally encapsulated" in that their mode of operation does not have access to high-level information about what is likely to be seen or said: "a condition for the reliability of perception, at least for a fallible organism, is that it generally sees what's there, not what it wants or expects to be there. Organisms that don't do so become deceased". Fodor's discussion of informational encapsulation draws mainly upon the perception and comprehension of language, where the dominant view (in both artificial intelligence and experimental psychology) is that all kinds of semantic and pragmatic information are brought directly to bear upon the acoustic signal. Fodor's careful unravelling of what exactly the relevant experiments do and don't show should ensure that this free-forall approach is quietly dropped.

In sum, Fodor defends and extends a Gallist approach to the architecture of

\section{Use and abuse of racial differences}

\section{W.F.Bynum}

Race and Racism.

By Ruth Benedict.

Routledge \& Kegan Paul: 1983. Pp. 192. Pbk $£ 3.95$.

OF only one science could it be proposed that its two foremost American practitioners in the middle third of the present century were women. The science is anthropology and the women were Ruth Benedict (1887-1948) and her pupil Margaret Mead (1901-1978). Of the two, Mead undoubtedly had the larger measure of popular success, ultimately becoming a kind of media guru, venerated for her wisdom derived from the study of other societies but called into service in understanding her own. By contrast, Ruth Benedict was of a retiring disposition, and in any case, the fact that she was fourteen years older than her pupil meant that her own academic career was pursued at a time when women rarely occupied chairs in major universities.

Benedict was promoted to a full professorship at Columbia University only shortly before she died. Yet, her book Patterns of Culture (Houghton Mifflin, 1934) has been described as the single most influential work by a twentieth century American anthropologist. It has remained in print and been translated into fourteen languages. In this book, in measured prose and with remarkable insight, she used a series of case studies of American Indian cultures to develop a subtle thesis about the ways in which societies mould cognition that is more detailed, more tightly argued and better supported by experimental evidence than Gall himself could have dreamed of. Even at the height of his fame as an anatomist, no respectable scientist would overtly admit the validity of Gall's approach to the fractionation of the mind. Jerry Fodor has never been noticeably respectable, thank goodness; he writes too amusingly for that. But the thesis Fodor advances is the current monograph may well be right. And that, plus having written the most lucid and incisive analysis of theoretical psychology thus far conceived, should be consolation enough.

John C. Marshall is in the Neuropsychology Unit, part of the Neuroscience Group at the Radcliffe Infirmary, Oxford.

the individuals born into them. She pointed out that not just the values and mores, but the perceptions and behavioural strategies can be radically divergent in different cultures: and in her particular case studies, in people who, biologically speaking, belong to the same 'race'.

By the time Benedict published her magnum opus, the Nazis had already come to power, though her book made no reference to the wider world of European politics. Its message, however, was consistent with that of Race and Racism, reprinted now after forty years. Originally published in a somewhat fuller version in America in 1940 as Race: Science and Politics, this book was explicity written for a world drawn into a war in which racism played a central role. Benedict's aims were clear: to explode the myth that race and culture ever have been or ever can be congruent entities, and to argue, using biology, psychology and history, that race can never be used as a valid basis of categorizing individuals.
Prefiguring death - a sketch of Ruth Benedict in 1948 by Erick H. Erikson (from An Anthropologist at Work by Margaret Mead, Houghton Mifflin).

\section{IMAGE \\ UNAVAILABLE FOR COPYRIGHT REASONS}


Race, Benedict insisted, is a biological fact; it can be studied using ordinary laboratory techniques. One's 'race' is genetically determined at conception, just like one's sex. The investigation of race and racial differences is a laudable enterprise, for it can teach human beings more about themselves and Benedict was sanguine enough to believe that self-knowledge was a salutory goal. Despite the biological reality of race, however, she pointed out that scientific efforts to divide the human species into particular races could never yield any universally satisfactory result, because of what she called the 'mingling of peoples'. The nature of history was such that 'pure' races do not actually exist, and the larger the racial grouping (such as tripartite division into Caucasian, Mongoloid and Negro), the fewer the physical characteristics which can be more or less consistently accommodated. Further subdivision permits the taxonomic inclusion of additional characters, but at the price of an increasing number of anomalies.

Two particularly cogent themes emerged from Benedict's reflections on the nature of race and racism. First, she was firm that there was no evidence of a difference in intelligence between the various races. Variation in performance on intelligence tests she attributed entirely to cultural or social factors. For instance, some cultures hold that it is impolite to answer a question unless one is absolutely and unassailably certain. Members of these groups will uniformly score badly on conventional intelligence tests. In other cases, scores improve dramatically when the children of a race (e.g. Black Americans) are offered the social and educational opportunities of the Northern United States, instead of the South. She did not discount the possibility that there are significant genetic components to intellectual capacity, but individual variation was so great and human beings so culturally pliable that generalizations based on race were meaningless. She based her statements on research done in the 1930 s, but modern readers will find her discussion topical.

A second theme addressed the issues surrounding the rise of Nazism and the 'Aryan myth'. Her point, argued primarily from history, was that racism (the notion that one group has the stigmata of superiority and the other has those of inferiority) was a relatively modern phenomenon without biological foundation. It was, as she put it, the 'new Calvinism'.

Although Benedict wrote as a scientist, her inclinations, one senses, were really

The next review supplement to appear in Nature will be Christmas Books on December 1 .

Books to be reviewed include Computer Images: The State of the Art by Joseph Deken, The Stars and the Stones by Martin Brennan, Landscapes of the Night: How and Why we Dream by Christopher Evans and Fossils: the Key to the Past by Richard Fortey. those of a humanist. (It could be argued that the two designations are not incompatible.) She had a passionate commitment to human dignity and equality, and four decades of debate and research have done nothing to detract from the essential core of her analysis.

A foreword by Professor John Rex puts this little book into contemporary pers-

\section{Neural \\ counterpoint}

\section{Steve Blinkhorn}

The Throwing Madonna: Essays on the Brain.

By William H. Calvin.

McGraw-Hill: 1983. Pp.253. Hbk \$13.95; pbk \$7.95.

SOME see popular science as simply the dissemination, in a stripped-down form, of what one might call regular science. 'Sexy' science has a simplified outline. There are many styles in which this is done, from Scientific American didactic, through Cousteau's heavily personalized 'denizens of the deep' approach to Reader's Digest 'I am John's lateral geniculate nucleus'. On the other hand there is a genre which seeks to dance a light-footed counterpoint to regular science, to act not merely as a means of transmission but to add to and cast into new perspectives what lies unloved by all but a few in the more impenetrable journals.

The Throwing Madonna is a case in point. If one can get past the title and stomach the overly self-conscious, occasionally arch and always unlovely prose style, one finds a thesis advanced, a point of view explored and a deal of loosely related material drawn together by the overall theme of "Essays on the Brain".

The thesis, that handedness, stonethrowing, the development and control of language and the practice of mothers carrying infants on the left arm, are linked in the origins of our species belongs to what one might call speculative evolutionary paleoanthropology. This is a field refractory to attempts at empirical disconfirmation, and rich in connotation. It is the world of the artist's impression, in which hominids more hirsute than ourselves are busy inventing tools in the foreground, whilst in the background still more hirsute apes look on uncomprehending, but somehow sullenly envious. Calvin's peculiar merit is that he pursues his thesis into the structure and function of the cerebral cortex of modern man, in a way which holds out the distant prospect of a solid evidential basis for his ideas.

Once into the modern brain he is considerably more at home, examining the relevance or otherwise of the digital computer as a metaphor for the brain, pective, and two statements on the biology of race prepared in 1964 and 1967 by scientists convened by UNESCO round out the volume, which retains interest both as a period piece and as a clear exposition of its subject.

W.F. Bynum is at the Wellcome Institute for History of Medicine, London.

dislodging the action potential from its preeminent place in the process, and ranging over tic douloureux, schizophrenia and the inadequacy of funding for research in his subject. But all too often one finishes an essay with a sense that more might (and should) have been said, and the considerable unevenness of style suggests that if the book of essays has indeed reached maturity as a form, then Calvin is not its most practised exponent.

There is a point of view that works such as this are essentially disreputable, a kind of intellectual self-indulgence which has no place in the rigorous world of science. The contrary view, that it is in the less disciplined exposition of ideas which ultimately drive more rigorous research that the sense and direction of science are found, receives some support from this at times engaging collection. It is a modest product, worth its modest price.

Steve Blinkhorn is Director of the Psychometric Research Unit, Hatfield Polytechnic, UK. ADVERTISEMENT

Published on the centennial of the eruption Krakatau 1883

\section{The Voleanic Eruption and lis Effocts}

TOM SIMKIN AND RICHARD S. FISKE

History's most famous eruption, with:

- Ashfall over $6000 \mathrm{~km}$ away

- Sea waves over $30 \mathrm{~m}$ high

- Explosions heard $4653 \mathrm{~km}$ away

- Dramatic sunsets around the globe

- Return of life to island remnants

These events are described in the words of 88 eyewitnesses and interpreted in 28 selected scientific accounts written over the last 100 years.

464 pp., 139 figs., 49 full color illus. Cloth: ISBN 0-87474-842-9 \$25.00

Paper: ISBN 0-87474-841-0 $\$ 15.00$

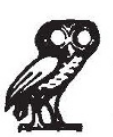

Order from:

Smithsonian Institution Press P.O. Box 1579

Washington, D.C. 20013

International orders accepted. All orders must be prepaid by check, money order, or credit card in U.S. dollars only. 